\title{
Multi-demand Oriented Research on Engineering Education Mode
}

\author{
Deng hongzhong ${ }^{1, a}$, Li mengjun, Chi yan, Tan siyu \\ ${ }^{1}$ College of Information System and Management, National University of Defense Technology, \\ Changsha, Hunan, P.R. China, 410073 \\ ahongzhongdeng@163.net
}

Keywords: Higher engineering education, Course system, Network, Modelling

\begin{abstract}
Under the impact of economy internationalization, the cruel market competition brings many new requirements on enterprise and higher engineering education. After the analyzed of status quo, problem on higher engineering education of our country, the paper discussed the require character of society on advance engineering education, proposed a course system analyze method, network modelling method and Multi-demand Oriented knowledge elective method. Bring a new idea for higher education innovation and student ability culture.
\end{abstract}

\section{Introduction}

With the development of our country economy, the demand of high quality and capability worker in enterprise increase quickly [1]. The demanded character, such as diversity, hiberarchy, complexity become obviously. While many enterprises can't find workers, lots of high school graduate lose job at the same time. The contradiction between supply and demand, especially the constructional problem between the high school student culturing and social capability demand become sharper. Engineering education, as a main way to develop engineering, technical and management personnel for our country economy developing, will help people in resolving these problems. How to culture high quality, useful personnel the enterprise need is the main task for engineering education reform.

\section{Problems in engineering education}

\subsection{Status in quo of engineering education}

From 1999, Chinese college began to expand their student number to meet the call for government reform. From 1999 to 2010, the number of registered students in high school increased about $16.2 \%$ each year. In 2010, high school recruited about 6.618 million students. The students in campus reach 22.318 million. In the year of 2002 and 2005, state departments also hold meetings for vocational education and put it in education projects. Higher education and vocational education developed quickly in recent year. With the progress of our higher and vocational education, new problem and contradiction also emerged out.

\subsection{Main problems in engineering education}

2.2.1. Sharp contradiction in talents supply and demand. In recent year, there exists a phenomenon that many high school graduates can't find suitable work and employment rate is low, while many enterprises can't recruit enough needed talents. The main reason is that high school graduate can't meet the demand and requirements of enterprise and market. Many in dire needed new, intercross specialties are seldom.

2.2.2 Teaching system can't adapt to the characteristic of engineering education. In a long time, the teaching system is divided and arranged by foundation courses, specialized core courses and major courses, which lacks changes needed to adapt to modern engineering education. The foundation courses and even a large part of the specialized core courses are organized by scientific education idea, in which the completeness of discipline system is mainly considered and rearrangement according to the need of engineer is not taken [2]. 
2.2.3 The students have narrow knowledge and weak ability. Many students study using old mode and manner used in senior high school, which is passive in knowledge acquisition. At the same time, they generally lack of correct thinking, communication and independent questions raise ability, let alone the creative thinking ability.

\section{Requirement analysis of engineering education}

From the above analysis and sum-up of engineering education in China it can be concluded that the important reason for these phenomena is that the training system of colleges and universities can't meet the quick change and multiplayer requirements of the enterprises. Education neglecting market rules results in the students not in badly need of the market. So it is necessary for higher engineering education to analysis the talents needs of the society and the enterprises.

Generally speaking, the requirements of present society and enterprises for engineering talents are:

\subsection{Synthesized knowledge structure requirements}

In modern society, engineering technicians are required to have not only systematic and complete basic theory but also the ability to present the most perfect technique solutions from the economic, ecological and sociological points of view. At the same time, they are also required to have specific knowledge and other interdisciplinary knowledge, among which lateral relations among different disciplines, departments and majors are emphasized, especially the cross development among different disciplines.

\subsection{Diversified ability requirements}

With economic globalization, fierce market competition put forwards new and diversified requirements and challenges to enterprises, which will force them innovate in technologies, improve on production techniques, optimize the organization structure and develop new products flexibly fit for the requirements of the consumers. So engineers in the enterprises need to have the abilities of not only systematic thinking, product research and process research, but also organization, management, marketing and problem solving.

\subsection{Differentiated learning requirements}

Modern students are rich in thoughts and ideas, they select learning points and direction according to their development plan and interests. Some want to master all the knowledge for graduate school. The differentiated and multi-level demand generally exists in colleges and universities, the traditional teaching method of inculcating knowledge into the students' brain can't fit for the differentiated learning demand of modern students, so the course set and knowledge point arrangements should be reformed accordingly [5].

\section{Multi-level requirements oriented Engineering education mode design}

Aiming at the multi-level requirements of modern society to higher engineering education, engineering colleges who take the task of engineering education reform should inspect and reform on their teaching objectives and methods. They need to lay emphasis on the quantity and quality of the knowledge, which can be favourable to exert the students' subjective initiative. They should make the students know the inherent relations among the courses and the logical structure of course system, so that the students can select elective courses and correlative knowledge freely and flexibly according to the need of themselves and future work. The responsibility of the colleges is to describe the system and knowledge structure of the courses to the students clearly and provide scientific selecting method, otherwise the knowledge the students selected may be unsystematic, which will lead to learning difficulty and knowledge structure brokenness of the students. So the two main jobs of colleges are:

\subsection{Modulation of courses' knowledge system and structure}

Many courses in higher school have complex relations with each other: Some are different aspects of the same problem, some are pilot courses of others, some are extends of others. These 
relations among courses need to be modelled in such a direct way that they can be expressed clearly for the students to choose.

Modulation of courses' knowledge system and structure includes:

Step 1: Analysis of the possible relation types existing among courses. Courses of the same major may have many relations. For example, advanced mathematics is pilot course of probability theory and mathematical statistics, so students must have learnt the former before learning the latter. Analyzing the relation types among courses is to find out the possible relation types existing in many courses. Especially in some major courses whose contents may intersect with each other, there may be several different relations and are difficult to be analyzed.

Step 2: Clear the interrelations of all the courses and build up planar network model of courses knowledge system. According to the relation types analyzed in step 1, select out all the courses having the same relation type and build up the planar network model based on these courses in a form of network diagram.

Step 3: Build up the multidimensional network model of the courses knowledge system. As many types of relations may exist simultaneously among courses, several planar networks built up in step 2 which are based on different relation types can be coupled into one multidimensional network model of the whole courses knowledge system. The multidimensional network of courses knowledge based on the above three steps must be a directed one with heterogeneous edges.

\subsection{Multi-level demands oriented course knowledge elective method}

The traditional teaching method of inculcating knowledge into the students' brain throughout the whole course can hardly meet the needs of both sides. One possible scheme for solving this problem is that the students select optimal course combination meeting with the demand according to their foundation to learn. This learning pattern looks like consulting a dictionary: According to reality or the need of future work, the students select correlative courses or part of the knowledge points to learn, and consider their own characteristics at the same time.

The biggest problem of the multi-level requirements oriented course selecting method is the unsystematic combination of the selected courses. For example, the student selects probability theory without the foundation of advanced mathematics, or selects information system development without the foundation of program design, or selects one or two courses on a certain knowledge aspect in isolation and can't build up its knowledge framework after learning.

So multi-level requirements oriented course elective method needs:

Step 1: Demand analysis. Analyze the characteristics of demands and requirements planning to reach.

Step 2: Making elective rules according to the demand characteristics. That is to say, decide the learning object as knowledge points, knowledge area or knowledge profound. If the object is knowledge points, then the core knowledge of the key courses can be selected. If the object is knowledge profound, then the main courses, core courses and corresponding key knowledge points should be selected and learnt deeply.

At the university level, students begin to select main learn points and directions according to their interests. Different students have different interests and different abilities, which lead to different learning requirements and objects to the course of engineering economics. Aiming at the differentiated requirements, we mainly teach the fundamental knowledge and introduce extended contents at the same time. The exercises after class include obligatory ones and optional ones. The obligatory exercises are the basic knowledge and techniques for all students to master, so they must be done entirely. Equivalence calculation is such exercise. The optional exercises are mainly investigative, case analysis and other deep-seated problems were not referred to in the textbook, for example, the case of second hand car price evaluation is associated with the compound depreciation problems in the chapter of depreciation. This multi-level oriented education mode not only lightens the learning burden of those who have few interests in the course, but also meets the need of those who have high requirements on it. 


\section{Conclusion}

With the rapid economic development of our country, internationalization has been reinforced; the social requirements on the quality of engineering talents are becoming higher and higher. Aiming at the current status and main problems of higher engineering education in China, this paper presents course system relationship analysis, course system networked modelling method and multi-level requirements oriented knowledge selecting method through analysis on the knowledge requirements of society, enterprises and students, which provides new idea for the country's engineering education and students training.

When putting this method into practice, it is found that the method can meet the differentiated and multi-level requirements of society and students on knowledge exactly. But the networked modeling of course knowledge system requires comprehensive, deep and systematic understanding of all the courses and knowledge, so it is necessary to gather the experiences of many professors to build up such a knowledge network model, and the veracity of the model have great influence on the effect too. Anyway, the modelling of knowledge system needs to be studied deeply.

\section{References}

[1] WANG J 2012Major characteristics and reform measures of higher engineering education in modern Germany. Chinese electric education

[2] ZHANG M. Current situation and prospect of engineering education. http://www. Xchen .com.cn/gclw/gcjylw/ 603144.html.

[3] WU Q D 2012 Problems, challenges and study of Chinese engineering education. Engineering education research center, Tsinghua University

[4] WANG L X 2012 Dilemma and trend: Reflection on the existing problems of Chinese engineering education. http://www.studa.net/ gaodeng/ 120307/11274338-1.html

[5] DENG H Z, GUO T D, LI M J 2011 The Research Teaching of Engineering Economy. High education research transaction. 